\title{
Lentivirus-mediated shRNA interference of (1) CrossMark clusterin blocks proliferation, motility, invasion and cell cycle in the ovarian cancer cells
}

\author{
Yanxia Fu', Yingrong Lai ${ }^{2 \dagger}$, Junfeng Liu ${ }^{2 \dagger}$, Xingyang Liu', Zeshan You ${ }^{1}$ and Guofen Yang ${ }^{1 *}$
}

\begin{abstract}
Background: In a previous analysis on the patients with ovarian cancers, we have found that clusterin is a biomarker associated with ovarian cancer in vivo and may be a prognostic factor associated with adverse outcome. Here, we explored the effect of lentivirus-mediated shRNA interference of clusterin, investigated whether clusterin was associated with adverse outcome of ovarian cancer cells in vitro.

Methods: OVCAR-3 and TOV-21G cell lines were infected with the lentivirus for delivering clusterin shRNA, and the stably transfected cells were selected. The effect of clusterin silencing was detected by western blotting assay. The proliferation, clonability, migration, invasion and cell cycle of two cell lines were detected separately by MTT assay, clone formation assay, scratch assay, transwell assay and fluorescence-activated cell sorting.

Results: Following clusterin silencing with shRNA, the expression of clusterin in two cell lines were decreased. And the proliferation, clonability, migration, invasion of these two cell lines were down-regulated apparently. The cell cycle of two cell lines was disturbed, cells in G1 phase was increased, but cells in G2 and S phase was decreased.
\end{abstract}

Conclusions: The expression of clusterin is significantly correlated with the biological characteristics of ovarian cancer cells, it may be a potential molecular for ovarian cancer treatment.

Keywords: Ovarian cancer, Clustein

\section{Introduction}

Ovarian cancer, a major cause of death in all gynecologic malignancies, is one of the most common malignancy in women worldwide and is the fourth leading cause of death from malignant disease [1]. Recently, the incidence of ovarian cancer has been increasing in China, Singapore and other countries [2]. With optimal surgical treatment and standard chemotherapy, the 5-year survival rate of ovarian cancer patients has improved significantly [3]. Nevertheless, the preliminary success in tumor regression and recurrence can't prevent resistance to further chemotherapeutic treatment. Development of this further resistance suggests the major limitation to the treatment. Hence, there is a crying need to look for a suitable solution for further treatment.

\footnotetext{
* Correspondence: pgf_yang@126.com

${ }^{\dagger}$ Equal contributors

'Department of Gynecology, The First Affiliated Hospital of Sun Yat-Sen University, Guangzhou, China

Full list of author information is available at the end of the article
}

Recently, the molecular targeted drug and treatment is widely used in tumor treatment. Lots of reports show that there are many specific genes which related to tumor genesis and development of the ovarian cancer, such as CIP2A [4], HOX [5], BRIP1 [6], EIF5A2 [7] and Bmi-1 [8]. Our previous studies suggested clusterin was probably another gene relevant to the treatment of ovarian cancer.

Clustein is a highly conserved, heterodimeric-secreted glycoprotein, which is encoded by a single copy gene located on chromosome 8p21-p12. Clustein is known as apolipoprotein J, estosterone-repressed prostate message2 , or sulfated glycoprotein-2. Clusterin gene expression is complex, appearing as different forms in different cell compartments [9]. Recent studies indicated that clusterin gene expressed in kinds of human tumor cells, including liver cancer cells, prostate cancer cells, colon cancer cells and bladder cancer cells [10-13]. The clusterin expression 
was up-regulated in all these cells, and the level of expression was closely related to the tumorigenesis of the tumor.

Previous research reveal clusterin was up-regulated in the ovarian cancer cells and the overexpression of clusterin did affect the tumorigenesis of the tumor [14]. To further study the function of clusterin, we silented the clusterin gene of ovarian cancer cells with the lentivirus vector in vitro and detected the clusterin gene expression in silenced-tumor cells. Moreover, we assessed the proliferation, migration, invasion, clonability, cell cycle of ovarian carcinoma cells after clusterin gene silencing.

\section{Materials and methods}

\section{Cell line and culture conditions}

Human ovarian cancer cell lines OVCAR-3 and TOV$21 \mathrm{G}$ were obtained from Sun Yat-Sen University Cancer Center (Guangzhou, China). Human ovarian cancer cell lines HO8910 and HO8910PM were purchased from Shanghai cell bank of Chinese academy of sciences. OVCAR-3, HO8910 and HO8910PM cells were growth in RPMI1640 mediumwith $10 \%(\mathrm{v} / \mathrm{v})$ fetal calf serum, streptomycin $(100 \mathrm{U} / \mathrm{ml})$ and penicillin $(100 \mathrm{U} / \mathrm{ml})$. TOV21G were growth in MCDB105, Medium199 mixed Medium (1:1) with $10 \%(\mathrm{v} / \mathrm{v})$ fetal calf serum, streptomycin $(100 \mathrm{U} / \mathrm{ml})$ and penicillin $(100 \mathrm{U} / \mathrm{ml})$. RPMI1640 medium, fetal bovine serum (FBS) and Dimethylsulfoxide (DMSO) were purchased from Gibco Biotechnology (Gibco-BRL, MD, USA). MCDB105, Medium199 were purchased from Sigma (USA). Cultures were maintained at $37^{\circ} \mathrm{C}$ in an incubator with a humidified atmosphere of $5 \% \mathrm{CO}_{2}$.

\section{Western blotting to analyze the clusterin gene expression in tumor cells}

For western blotting analysis, cells were seeded in 6-well plates at $2 \times 10^{5} /$ well. Cells were grown to $90 \%$ confluence and were lysed in cell Lysis solution (RIPA: PMSF $=100: 1$ ) for $30 \mathrm{~min}$ and were transferred to $1.5 \mathrm{ml} \mathrm{EP} \mathrm{for} 30 \mathrm{~min}$ on ice. Lysates were centrifuged at $12000 \mathrm{~g}$ for $30 \mathrm{~min}$ to remove nuclei and precipitates. Supernatant protein concentrations were measured using the Bio-Rad protein assay (OD:562 nm) with BSA in lysis buffer as a standard. Cell lysates were loaded into each well containing SDSPAGE and transferred to nitrocellulose membranes. The protein concentration were adjusted to $40 \mu \mathrm{l}$. Membranes were blocked for $2 \mathrm{~h}$ at room temperature in $0.1 \%$ TBS with $5 \%$ non-fat milk, and probed using Clusterin antibody (1:100) purchased from Millipore (Billerica, MA, USA) and $\alpha$-tubulin (1:1000) as the internal control purchased from (Santa Cruz, CA, USA) overnight. After the membrane washing three times by $0.1 \% \mathrm{TBS}$, the secondary antibody was added and incubated $2 \mathrm{~h}$ at room temperature. Then the bands were visualized by an ECL kit (ThermoScientific Pierce).

\section{Lentivirus constructions}

ShRNA was designed by Shanghai Jikai gene Chemical Co., Ltd. (Shanghai, China) and referred to Clusterin Gene (NM_203339) of GeneBank. The PGCSIL-GFP, which is a third generation self-inactivating lentivirus vector containing a CMV-driven GFP reporter and a U6 promoter upstream of cloning restriction sites, was used in the shRNA silencing system. The synthetic oligonucleotide primers used were CLU; forward (5'CCGGGACCAGACGGTCTCAGACAATCTCGAGATT GTCTGAGACCGTCTGGTCTTTTTG-3') and reverse (5'-AATTCAAAAAGACCAGACGGTCTCAGACAATC TCGAGATTGTCTGAGACCGTCTGGTC-3'). The primers were annealed and linked into the cloning restriction site of the vector which had been digested with the restriction enzymes AgeI and EcoRI. After annealing, the double-stranded DNA was digested with EcoRI to linearize the pGCSIL-GFP vector. The negative control sequence (5'-ttctccgaac gtgtcacgt-3') was used as previously described. The NC-shRNA was designed; forward forward (5'-ccggaaccagagctcgcccttctacttcaagagagtagaaggg cgagctctggtttttttg-3') and reverse (5'-aattcaaaaaaaccagag ctcgcccttctactctcttgaagtagaagggcgagctctggtt- $\left.3^{\prime}\right)$. It has been proven to be efficient in Clusterin silencing experiments. Then it was co-transfected with pHelper 1.0 and pHelper 2.0 into $293 \mathrm{~T}$ cells to package and produce the shRNA expressing lentivirus. The supernatant was collected and concentrated $48 \mathrm{~h}$ after co-transfection. The titer of lentivirus targeting Clusterin (LV-CLU) and lentivirus targeting negative control (LV-NC) was examined by the hole by dilution titer method. The vectors and oligonuleotide primers were purchased from Genechem. To knock down the Clusterin in the OVCAR-3 and TOV-21G cancer cell lines, cells were seeded in a 6-well tissue culture plate with $2 \times 105 /$ well 1 day prior to infection. The complete culturesolution was replaced by infection enhancing solution with 5 $\mu \mathrm{g} / \mathrm{ml}$ polybrene (Genechem) and the packed lentivirus was added to cells with multiplicity of infection (MOI) 20 or 10. Twelve hours later, the lentivirus solution was replaced with complete culture solution. Infected cells were subcultured every 5-7 days [13].

\section{Test the infection and knockdown efficiency}

The human tumor cells grew well on the day prior to viral introduction was recovered, and were incubated with $5 \% \mathrm{CO}_{2}$ at $37{ }^{\circ} \mathrm{C}$. Following the incubation, the expression of GFP was observed under a fluorescence microscope. When the efficiency of infection exceeded $50 \%$, Cells were collected. The protein expression of 
clusterin gene were analyzed using western blotting as above.

\section{MTT assay and clone formation assay to detect the proliferation of ovarian cancer cells}

Cells were cultured in the 6 -well plates at $2 \times 10^{5} /$ well. When cells were grown to $80 \%$ confluence, they were trypsinized. The cell suspension was re-suspended in complete medium. Cells were counted and added in 96-well plate at 1000 cells/well. Each group, included three compound perforations, added $100 \mu$ complete medium. Cells were incubated with $5 \% \mathrm{CO}_{2}, 37{ }^{\circ} \mathrm{C}$. The growth of cells were tested with Enzyme immunoassay for four days. The data were collected and analyzed to create a proliferation curve.

Meanwhile, the suspending cells were transferred into six-well plate at 300 cells/well. Each well was added $2 \mathrm{ml}$ complete medium and comprised three compound perforations. Cells were incubated with $5 \% \mathrm{CO}_{2}$ and cultured at $37{ }^{\circ} \mathrm{C}$ until the cell clones could be observed directly. The medium was removed, methanol was added for $30 \mathrm{~min}$. Removing methanol, the clones were dyed with crystal violet for $30 \mathrm{~min}$ and counted.

Scratch assay and transwell assay to detect the migration and invasion of ovarian cancer cells

Cells were cultured six-well plate at $5 \times 10^{5}$ cells/well. Each well was added $2 \mathrm{ml}$ complete medium with $10 \%$
PFA and comprised three compound perforations. Cells were incubated with $5 \% \mathrm{CO}_{2}$ and cultured at $37{ }^{\circ} \mathrm{C}$. When cells were covered almost confluent, the surface of cells was scratched by the same pin and washed twice with PBS, allowed to migrate in RPMI1640 without FBS for $24 \mathrm{~h}$. Phase contrast micrograph images were captured immediately and $24 \mathrm{~h}$ later. The relative distance traveled by the leading edge from 0 to $22 \mathrm{~h}$ was assessed using Adobe Photoshop CS3 software (Adobe Inc.) $(n=6)$.

Cells were transferred into 24 -well plate at $5 \times 10^{4}$ cells/well and cultured as above for $24 \mathrm{~h}$. After trypsinized, cells washed with PBS and resuspended in RPMI-1640 without FBS. Samples of $5 \times 10^{4}$ cells were placed in the upper chamber of each Transwell device (Falcon, BD Labware, Bedford, MA, USA) with an $8-\mu \mathrm{m}$ Matrigel-coated polycarbonate membrane filter inserted in 24-well plates. RPMI-1640 with $10 \%$ FBS was placed in the lower chamber. After $24 \mathrm{~h}$ of incubation, the non-invading cells were removed by wiping the upper surface of the filter with a cotton swab. The remaining cells were fixed in $100 \%$ methanol for $20 \mathrm{~min}$, stained with Giemsa (Sigma), and rinsed with distilled water several times. The degree of invasion was quantified by selecting five different predetermined views (original magnification, x200) and counting the cells on the underside of the filters under a microscope [13].

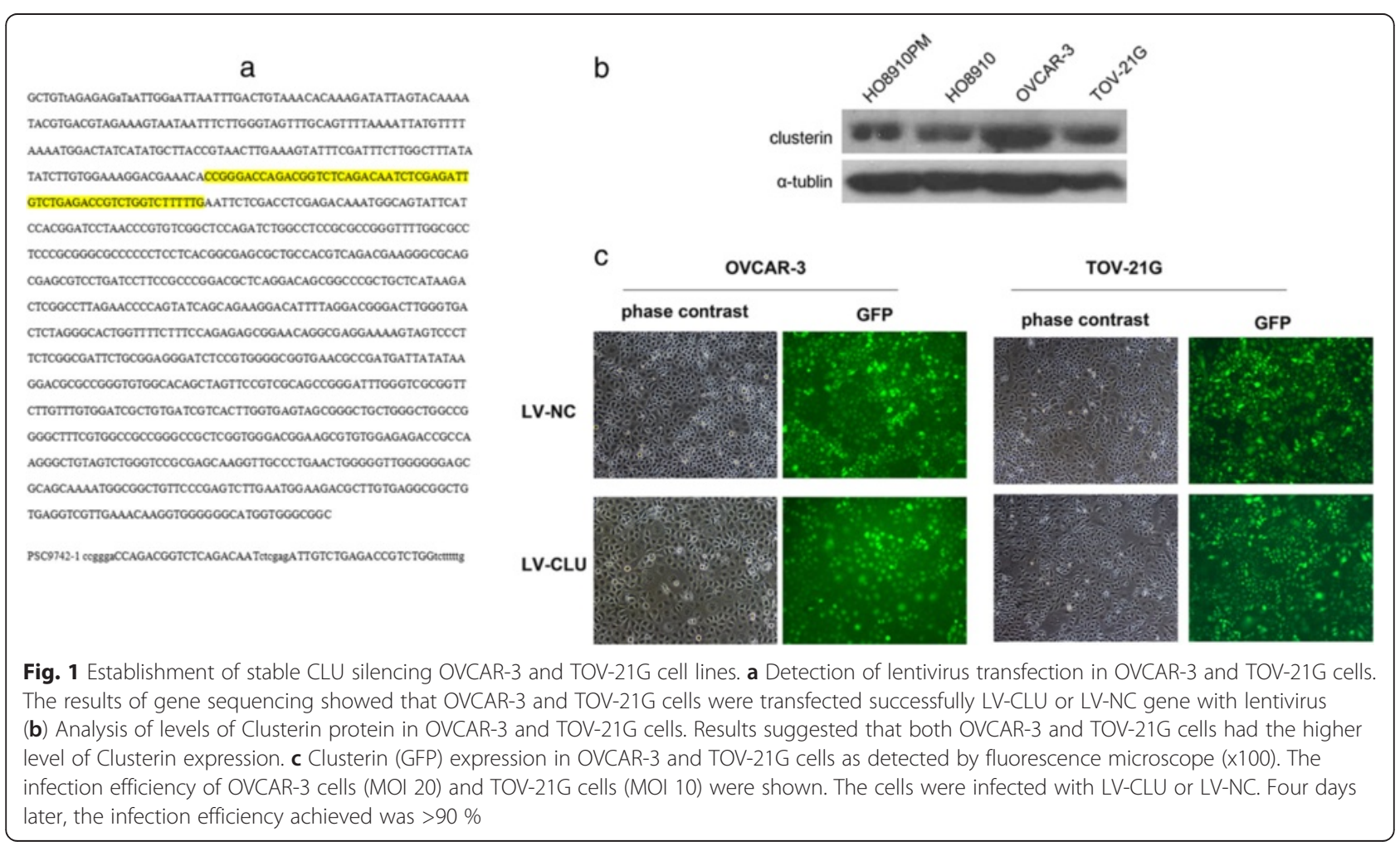


Fluorescence-activated cell sorting (FACS) to assess ovarian cancer cell cycle distribution following clusterin gene silencing

Cells were cultured six-well plate at $5 \times 10^{5}$ cells/well. The cell supernatant was collected when the coverage rate in the experimental group increased to $80 \%$, ensuring that cells were in the logarithmic phase. Cells were washed twice with PBS and subjected to trypsinization. Cells were collected in a $5 \mathrm{ml}$ centrifuge tube. Three compound perforations were prepared in each group and timed cycle tests were performed ensuring an adequate number of cells for computerized analysis, with at least 1,000,000 each time. Cells were collected after centrifugation at 2,000 $\mathrm{rpm}$ for $5 \mathrm{~min}$ and fixed with $70 \%$ ethanol, which was pre-cooled to $4{ }^{\circ} \mathrm{C}$ overnight. The stationary liquid was abandoned by centrifugation at $2000 \mathrm{rpm}$ for $5 \mathrm{~min}$. Cells were washed with PBS twice. Cells were incubated in PBS containing $400 \mu \mathrm{l}$ RNase $(50 \mu \mathrm{g} / \mathrm{ml})$ at $37{ }^{\circ} \mathrm{C}$ for 30 min. Cells were then stained with $800 \mu \mathrm{l} \mathrm{PI}(20 \mu \mathrm{g} / \mathrm{ml})$ for $30 \mathrm{~min}$ in the dark at $37^{\circ} \mathrm{C}$. Cell cycle progression was analyzed using a flow cytometer (Beckman Coulter, Miami, FL, USA). During cell cycle analysis, gating and voltage were carefully set to exclude clumped cells and cell debris. The data were analyzed using CXP Analysis 2.0 (Beckman Coulter).

\section{Statistical analysis}

All data are analyzed with the statistical software SPSS 16.0 and expressed as mean \pm standard deviation (SD). The significance level of statistics was set at $P<0.05$.

\section{Results}

The expression of clusterin protein in tumor cells

To select the cell lines with a high level of CLU expression, we used western blot analysis to analyze the Clusterin expression at the protein levels in HO8910, HO8910PM, OVCAR-3 and TOV-21G cancer cell lines. The results of the western blotting, which set $\alpha$-tublin as an internal reference, suggested that the clusterin protein was separately expressed in the HO8910, HO8910PM, OVCAR-3 and TOV-21G cells (Fig. 1b). The levels of clusterin protein were higher in the OVCAR-3 and TOV$21 \mathrm{G}$ cells than in the HO8910 and HO8910PM cells. It was found that the protein expression level of two cell lines was different, but was abundant.

Transfected with the shRNA lentivirus, GFP expression was observed under fluorescence microscopy (Fig. 1c). The infection efficiency of OVCAR-3 cells (MOI 20) and TOV-21G cells (MOI 10) were shown. The cells were infected with LV-CLU or LV-NC. Four days later, the infection efficiency achieved was >90\%. The level of GFP expression reached respectively the highest levels on the fourth day. To further, the gene sequence of the OVCAR3 and TOV-21G cells were sequenced (Fig. 1a). The levels of CLU protein in the OVCAR-3 and TOV-21G cells were detected by western blotting. The results showed that the levels of CLU protein were significantly lowered in cells of LV-CLU groups. However, there was no significantly influence in the NC-CLU groups (Fig. 2).

\section{Analysis of inhibition of the proliferation of ovarian cancer} cells following down-regulation of the clusterin gene

The proliferation of ovarian cancer cells were detected by MTT assay. After transfection with the shRNA lentivirus, the proliferation rate of OVCAR-3 cells in LV-CLU group was inhibited together with the NC-CLU control from the third day (Fig. 3). And compared with the NC-CLU control, the proliferation rate of TOV-21G cells in the LV-CLU group was inhibited from the second day (Fig. 3). The results show that down-regulation of the clusterin gene in two cell lines were obvious.

\section{Analysis of inhibition of the migration following clusterin} gene silencing

The migration of tumor cells were detected by scratch assay and observed under microscopes. The two groups were treated with a pin, respectively, for $24 \mathrm{~h}$. The cells

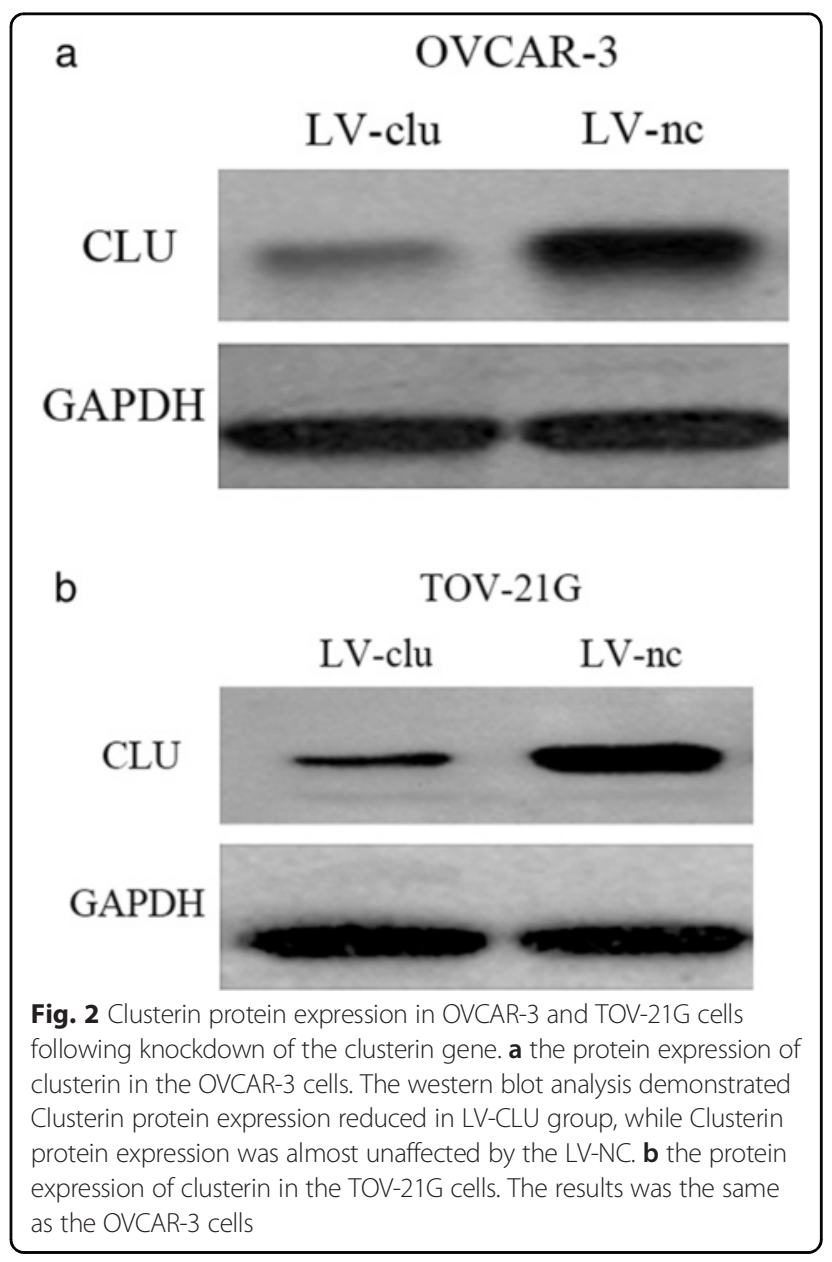


a

TOV-21G

\section{LV-NC}

\section{LV-CLU}
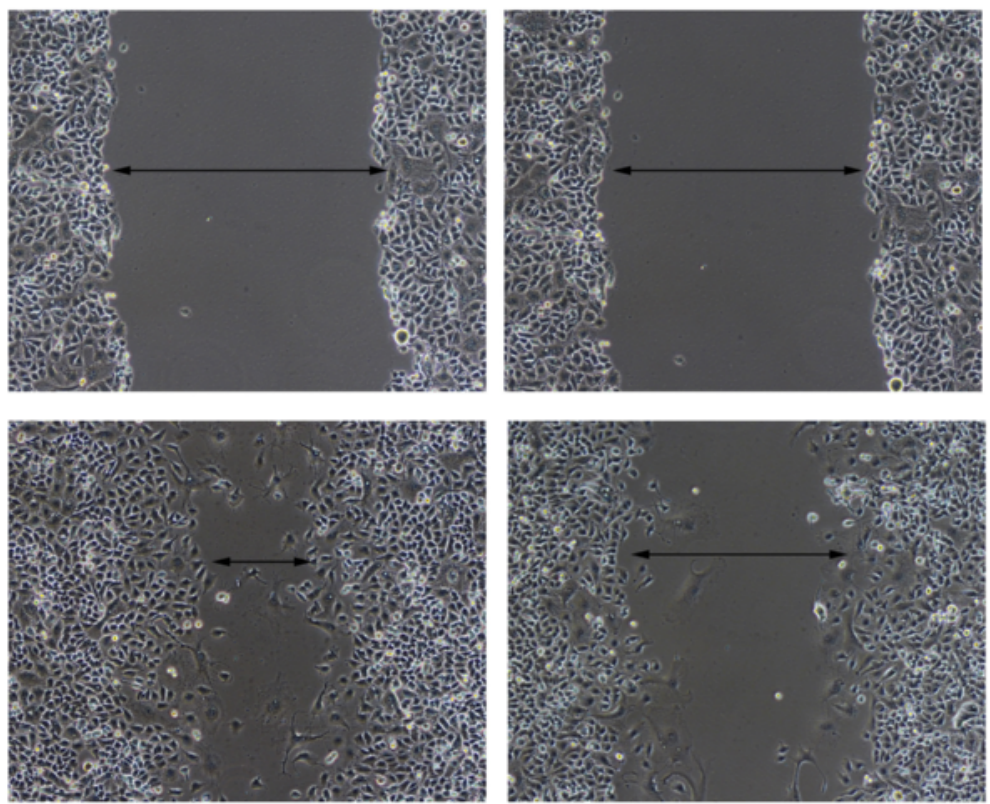

b

OVCAR-3
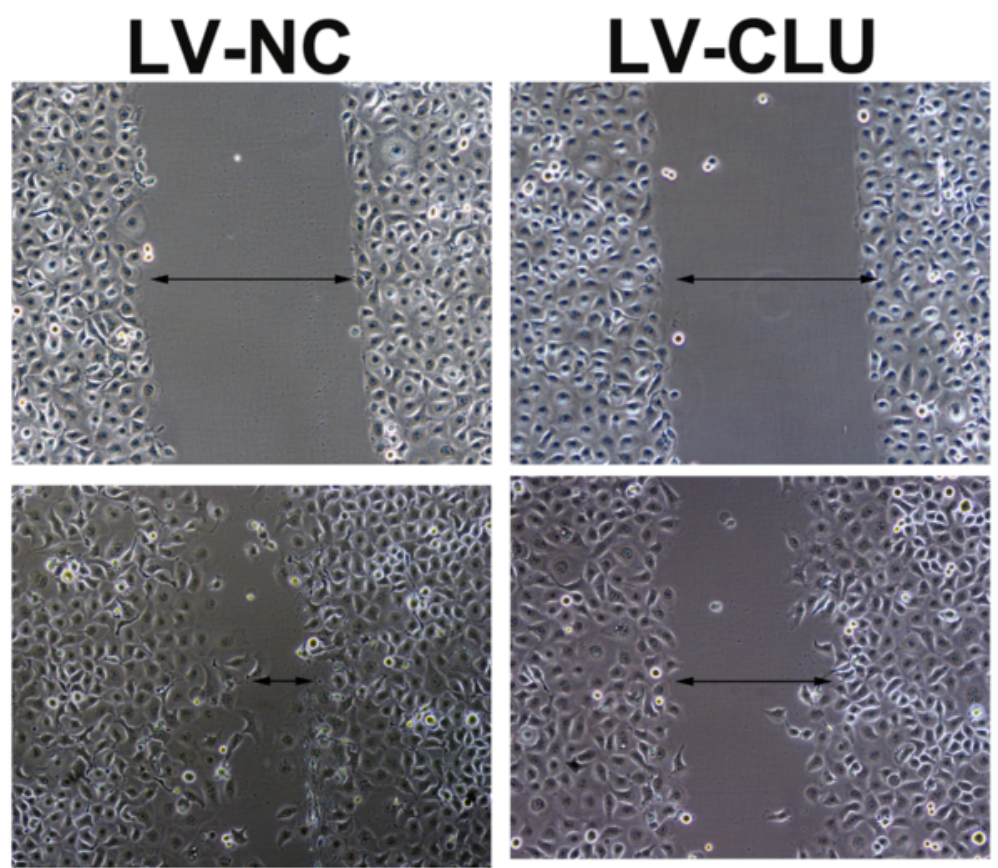

Fig. 3 The results of the migration following Clusterin gene silencing (a) A scratch assay was used to detect the migration ability of TOV-21G cells after Clusterin silencing. The two groups were treated with a pin, respectively, for 24h. The cells of LV-CLU group had a greater migrating distance compared to the cells of NC-CLU group. (b) A scratch assay was used to detect the migration ability of OVCAR-3 cells after Clusterin silencing. The results was similar to the TOV-21G cells 
of LV-CLU group had a greater migrating distance compared to the cells of NC-CLU group after $24 \mathrm{~h}$. The results was similar to the TOV-21G cells (Fig. 3). This results suggest that the migration of OVCAR-3 and TOV-21G cells after the transfection was diminished.

\section{Analysis of inhibition of the invasion following clusterin gene silencing}

Invasion is an important aspect that lead to the ability of cancer cells to metastasize. In our study, transwell assay was used to detect whether Clusterin silensing would affect cell invasion. Cells of LV-NC and LV-CLU groups were seeded in transwell chambers and cultured for $24 \mathrm{~h}$. The results demonstrated that cells of LV-CLU group had less invasiveness than cells of LV-CLU group. Statistical analysis revealed a significant difference between the LV-NC and LV-CLU groups $(P<0.01)$ (Fig. 4).

\section{Analysis of inhibition of the clonability following clusterin} gene silencing

We observed a decrease in the number of OVCAR-3 and TOV-21G cell colonies in the LV-CLU group after clusterin gene silencing. The number of cells in the colonies decreased relative to the NC-CLU control $(P<0.05)$ $(n=3)$ (Fig. 5). The results indicates that the clonability of OVCAR-3 and TOV-21G cells largely inhibited following the down-regulation of clusterin gene.

\section{FACS analysis of cell cycle following clusterin gene silencing}

After transfection with the shRNA lentivirus, the percentage of OVCAR-3 and TOV-21G cell cells in the G1 phase was significantly increased $(P<0.05)$, while cells in the $\mathrm{S}(P<0.001)$ and $\mathrm{G} 2$ phases decreased significantly $(P<0.05)$ in the LV-CLU group compared with the NC-CLU control (Fig. 6). The results indicates that silence of the clusterin gene was apparently related to regular distribution of the OVCAR-3 and TOV-21G cells.

\section{Discussion}

In recently reports, the expression level of clusterin was studied in normal ovaries, benign and borderline ovarian tumors, and malignant epithelial cancers. A significant

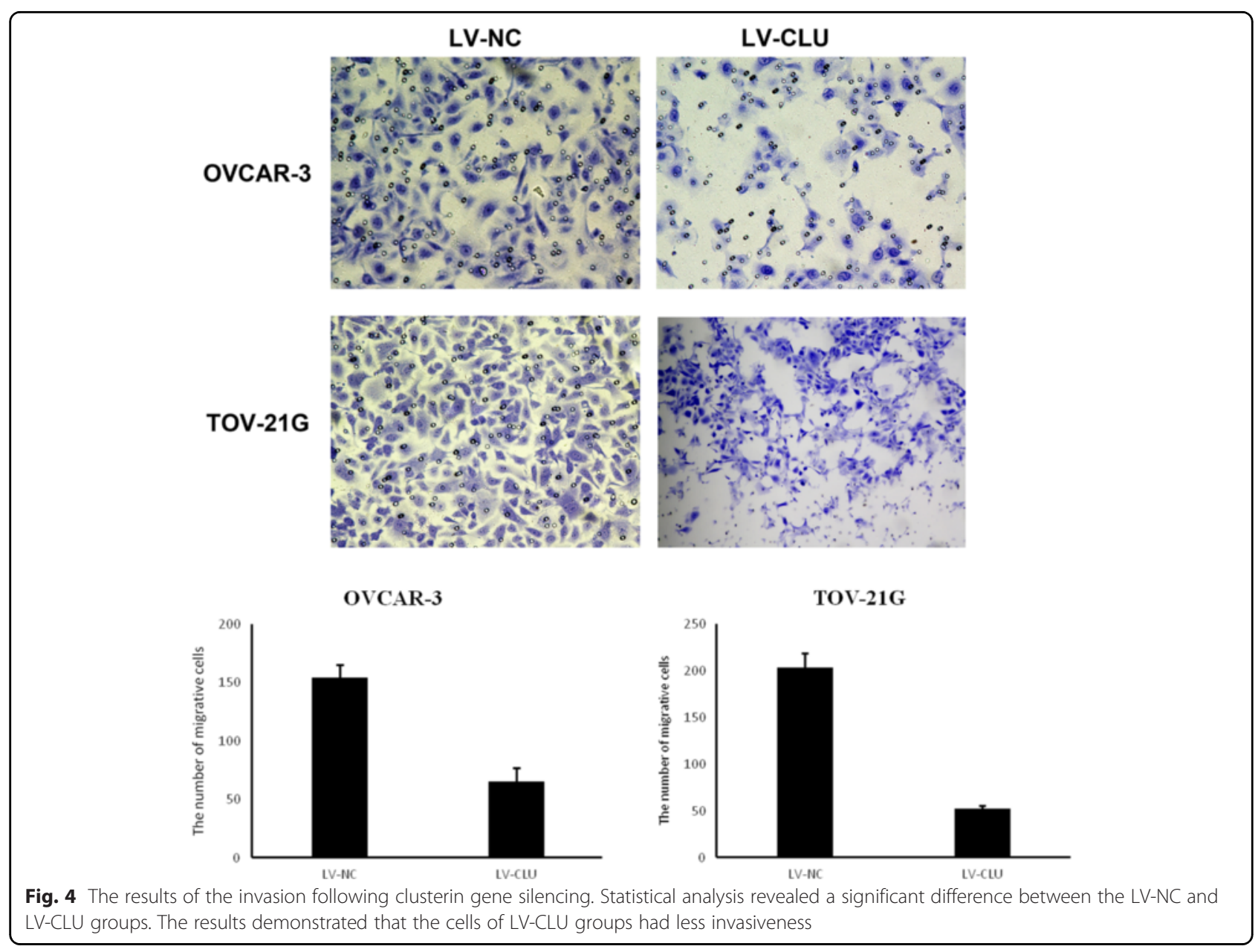


increasing cytoplasmic expression of clusterin was observed from the normal ovary, to benign cystadenoma, borderline tumor, and malignant epithelial carcinoma. These evidences suggest up-regulation of clusterin is associated closely with tumor progression [15]. The level of clusterin expression maybe is an important prognostic factor in the assessment of the aggressive nature of ovarian cancer [2].

Clusterin is an controversial molecule and it remains debatable about whether clusterin has multiple functions or only a single primary function influenced by cellular context [16]. It is not clear why clusterin play contradictory functions, such as cell survival, tumor progression, treatment resistance or cell apoptosis [17]. However, its functions in many cancer cells are certain. The level of clusterin expression in renal cancer cells was found to be closely associated with pathological stage and grade of the tumor, and the overall survival rate of patients with high clusterin expression was obviously lower than that of patients with weak expression [18]. The level of clusterin expression correlated with the level of estrogen and progesterone receptor expression, tumor size, and lymph node metastasis in breast carcinoma [19]. In colon carcinoma, clusterin has been used as a novel prognostic and predictive marker which is observed in aggressive tumors and metastatic nodules [20]. Similarly, clusterin expression is associated with FIGO stage and histological type in ovarian cancer [21]. Hence, through mechanisms not yet elucidated, it is certain that CLU biosynthesis is altered and up-regulated in cancer tissues.

In the preset study, we have showed that clusterin express highly in two ovarian cancer cell lines in vitro, while there is lower clusterin expression in the normal ovarian cells [14]. And the clusterin expression could be down-regulated with a lentiviral vector. Following the clusterin silencing, the clusterin expression was downregulated, and the proliferation, clonability of OVCAR-3 and TOV-21G cells were decreased, meanwhile, the migration and invasion of these cells also down-regulated. The cell cycle of these cells were changed. A large number of OVCAR-3 and TOV-21G cells were confined in G1 phase, only a small number of these cells accessed into G2 phase and S phase. In contrast, no-silencing cells had a strong clusterin expression. They had significantly higher abilities of proliferation, clonability, migration and invasion. Our data suggest that clusterin is an important protein associated with both cancer therapy and tumor development.

Our results also support that clusterin is a stressassociated anti-apoptotic protein that is up-regulated in an adaptive cell survival manner following various cell death trigger in ovarian cancer cells [22, 23]. More evidence suggests that clusterin enhance the resistance to cytotoxic chemotherapy and radiotherapy in breast cancer [24], lung cancer, cervical cancer, and prostate cancer.

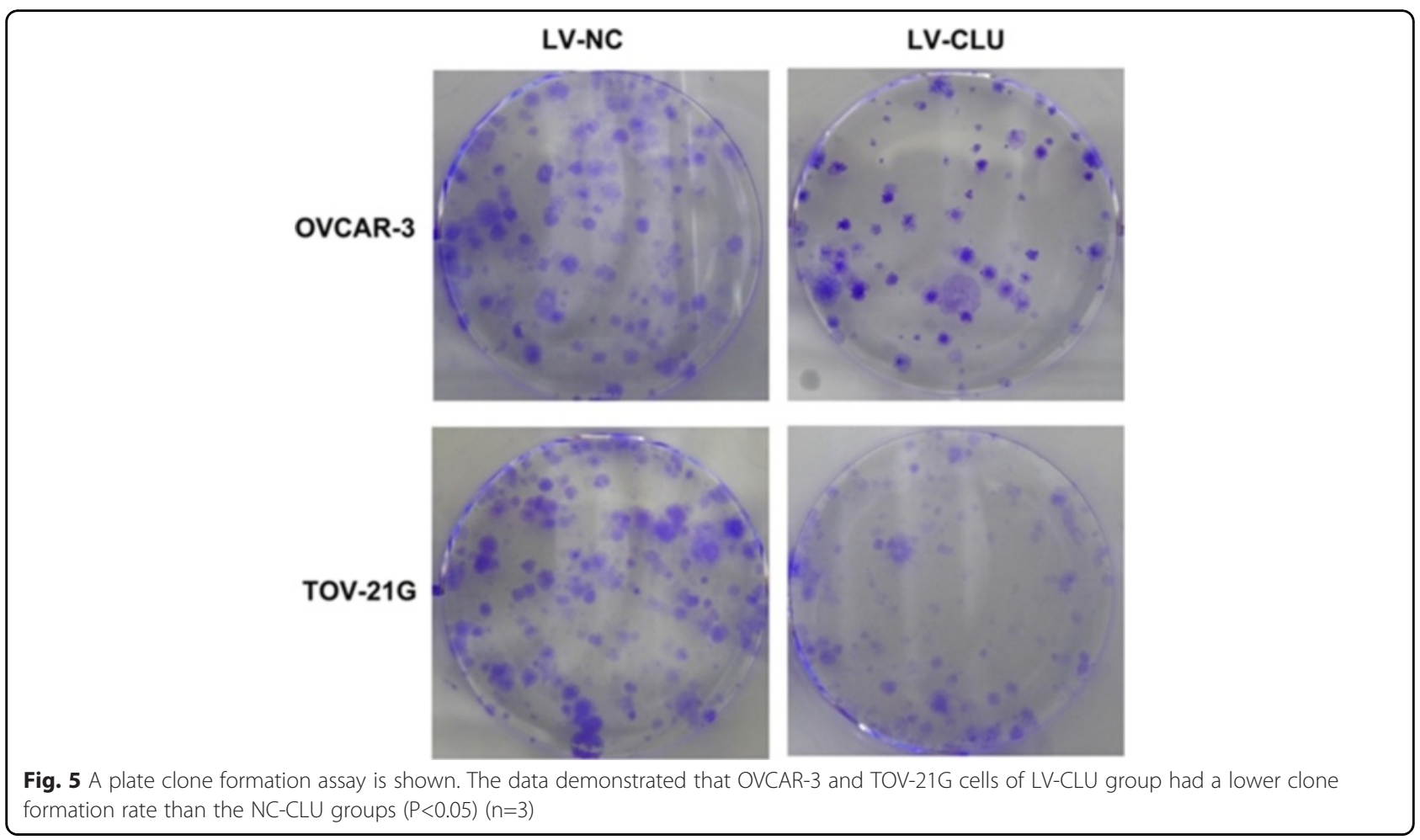




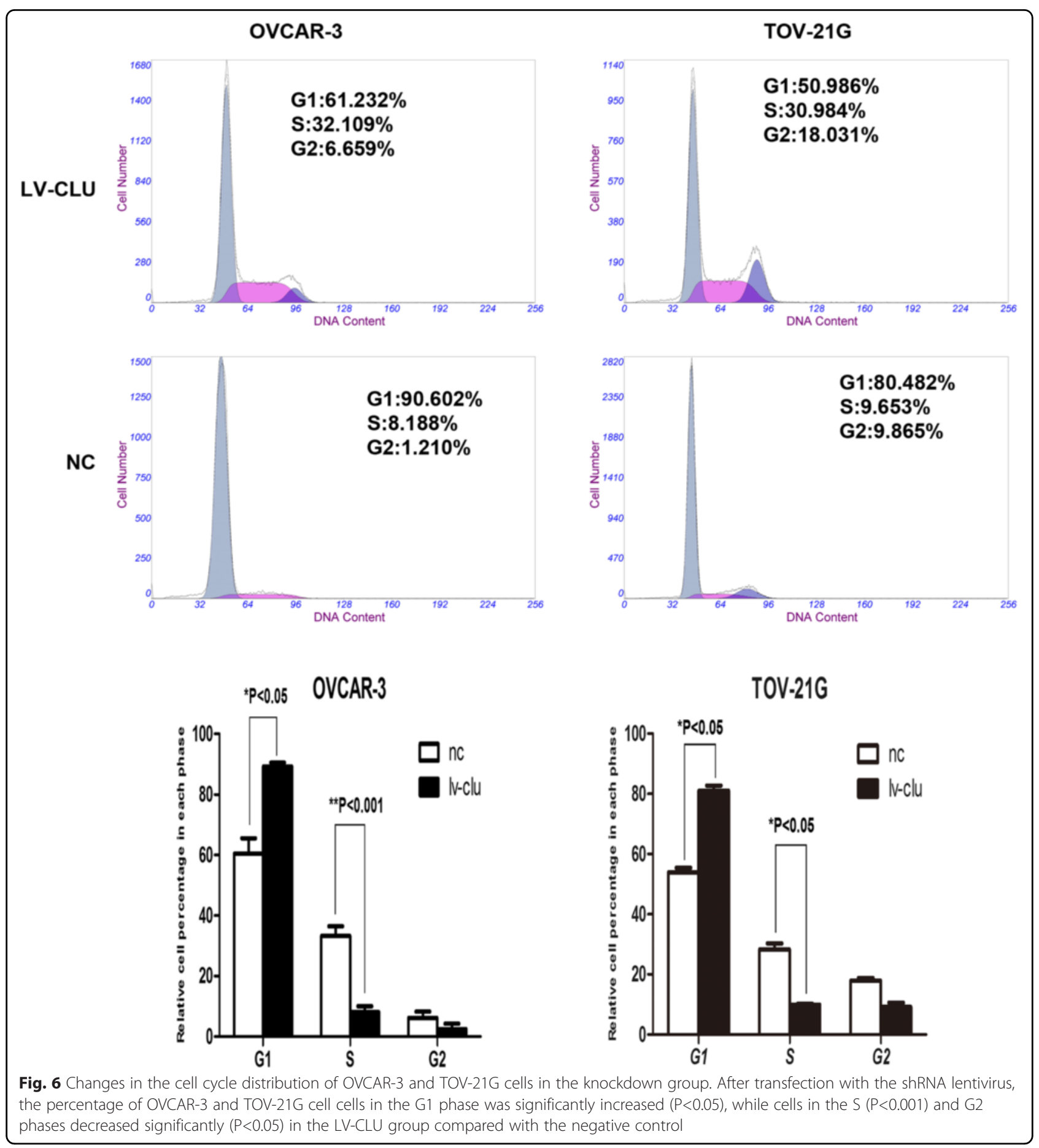

Therefore, silencing clusterin expression to overcome chemoresistance maybe is an novel therapeutic strategy.

\section{Conclusions}

In summary, present study demonstrated that the biogenesis of ovarian cancer cells was changed following the silence of clusterin. And the proliferation, clonability, migration, invasion and cell cycle of ovarian cancer cells are significantly correlated with the expression of clusterin. Therefore, clusterin could be a potential molecular for ovarian cancer treatment. Our study may be helpful to the development of new therapeutic regimens and improvement the subsequent survival in ovarian cancer patients. 


\section{Abbreviations}

shRNA: Short hairpin RNA; GFP: Green fluorescent protein; LV-CLU: Lentivirus targeting Clusterin; LV-NC: Lentivirus targeting negative control.

\section{Competing interests}

The authors declare that they have no competing interests.

\section{Authors' contributions}

YF carried out the molecular genetic studies, cell culture. YL carried out the functional test of cell lines. $J$ participated in the molecular genetic studies and draft the manuscript. XL performed the statistical analysis. FG conceived of the study. ZY participated in the functional test of cell lines. GY carried out its design and coordination and helped to draft the manuscript. All authors read and approved the final manuscript.

\section{Acknowledgements}

This study was support by the Nature Science Foundation of China (no. 81272855) and Guangdong Natural Science Foundation (no.s2012010008810).

\section{Author details}

${ }^{1}$ Department of Gynecology, The First Affiliated Hospital of Sun Yat-Sen University, Guangzhou, China. ${ }^{2}$ Department of Pathology, The First Affiliated Hospital of Sun Yat-Sen University, Guangzhou 510080, Guangdong, China.

Received: 8 January 2015 Accepted: 27 June 2015

\section{Published online: 21 August 2015}

\section{References}

1. Wingo PA, Ries LA, Rosenberg HM, Miller DS, Edwards BK. Cancer incidence and mortality, 1973-1995: a report card for the U.S. Cancer. 1998;82(6):1197-207.

2. Xie D, Lau SH, Sham JS, Wu QL, Fang Y, Liang LZ, et al. Up-regulated expression of cytoplasmic clusterin in human ovarian carcinoma. Cancer. 2005;103(2):277-83

3. Goff BA, Sainz de la Cuesta R, Muntz HG, Fleischhacker D, Ek M, Rice LW, et al. Clear cell cancer of the ovary: a distinct histologic type withpoor prognosis and resistance to platinum-based chemotherapy instage III disease. Gynecol Oncol. 1996;60(3):412-7.

4. Böckelman C, Lassus H, Hemmes A, Leminen A, Westermarck J, Haglund C, et al. Prognostic role of CIP2A expression in serous ovarian cancer. Br J Cancer. 2011;105(7):989-95.

5. Kelly ZL, Michael A, Butler-Manuel S, Pandha HS, Morgan RG. HOX genes in ovarian cancer. J Ovarian Res. 2011:9:4-16.

6. Rafnar T, Gudbjartsson DF, Sulem P, Jonasdottir A, Sigurdsson A, Jonasdottir A, et al. Mutations in BRIP1 confer high risk of ovarian cancer. Nat Genet. 2011;43(11):1104-7.

7. Yang GF, Xie D, Liu JH, Luo JH, Li LJ, Hua WF, et al. Expression and amplification of elF-5A2 in human epithelial ovarian tumors and overexpression of EIF-5A2 is a new independent predictor of outcome in patients with ovarian cancer. Gynecol Oncol. 2009;112:314-8.

8. Yang GF, He WP, Cai MY, He LR, Luo JH, Deng HX, et al. Intensive expression of Bmi-1 is a new independent predictor of poor outcome in patients with ovarian cancer. BMC Cancer. 2010;10:133.

9. $\quad$ Niu Z, Li X, Hu B, Li R, Wang L, Wu L, Wang X. Small interfering RNA targeted to secretory clusterin blocks tumor growth, motility, and invasion in breast cancer. Acta Biochim Biophys Sin (Shanghai). 2012;44(12):991-8.

10. Albert JM, Gonzalez A, Massion PP, Chen H, Olson SJ, Shyr Y, et al. Cytoplasmic clusterin expression is associated with longer survival in patients with resected non small cell lung cancer. Cancer Epidemiol Biomarkers Prev. 2007;16:1845-51.

11. Wu AJ, Park II, Zhaung L, Lee C. Response to a lethal dose of heat shock by a transient up-regulation of clusterin expression followed by downregulation and apoptosis in prostate and bladder cancer cells. Prostate. 2002;53:277-85.

12. Miyake H, Hara I, Gleave ME. Antisense oligodeoxynucleotide therapy targeting clusterin gene for prostate cancer : Vancouver experience from discovery to clinic. Int J Urol. 2005;12:785-94

13. Lu J, Luo JH, Pang J, Cao JZ, Wu RH, Tong ZT, et al. Lentivirus-mediated RNA interference of clusterin enhances the chemosensitivity of EJ bladder cancer cells to epirubicin in vitro. Mol Med Rep. 2012;6(5):1133-9.
14. Yang GF, Li XM, Xie D. Overexpression of clusterin in ovarian cancer is correlated with impaired survival. Int J Gynecol Cancer. 2009;19(8):1342-6.

15. Casey OM, Morris DG, Powell R, Sreenan JM, Fitzpatrick R, Powell R, et al. Analysis of gene expression in non-regressed and regressed bovine corpus luteum tissue using a customized ovarian cDNA array. Theriogenology. 2005;64(9):1963-76.

16. Trougakos IP, So A, Jansen B, Gleave ME, Gonos ES. Silencingexpression of the clusterin/apolipoprotein $\mathbf{j}$ gene in human cancercells using small interfering RNA induces spontaneous apoptosis, reduced growth ability, and cell sensitization to genotoxic and oxidativestress. Cancer Res. 2004;64(5):1834-42.

17. Wei L, Xue T, Wang J, Chen B, Lei Y, Huang Y, et al. Roles of clusterin in progression, chemoresistance and metastasisof human ovarian cancer. Int J Cancer. 2009;125(4):791-806.

18. Krüger $\mathrm{S}$, Ola V, Fischer D, Feller AC, Friedrich M. Prognostic significance ofclusterin immunoreactivity in breast cancer. Neoplasma. 2007;54(1):46-50.

19. Scaltriti M, Santamaria A, Paciucci R, Bettuzzi S. Intracellular clusterin induces G2-M phase arrest and cell death in PC-3 prostate cancer cells. Cancer Res. 2004;64(17):6174-82.

20. Pucci S, Bonanno E, Pichiorri F, Angeloni C, Spagnoli LG. Modulation ofdifferent clusterin isoforms in human colon tumorigenesis. Oncogene. 2004;23(13):2298-304.

21. Park DC, Yeo SG, Wilson MR, Yerbury JJ, Kwong J, Welch WR, et al. Clusterin interacts with Paclitaxel and confer Paclitaxel resistance in ovarian cancer. Neoplasia. 2008;10(9):964-72.

22. Hoeller C, Pratscher B, Thallinger C, Winter D, Fink D, Kovacic B, et al. Clusterin regulates drug-resistance in melanoma cells. J Invest Dermatol. 2005;124(6):1300-7.

23. Lourda M, Trougakos P, Gonos ES. Development of resistance tochemotherapeutic drugs in human osteosarcoma cell lines largelydepends on up-regulation of Clusterin/Apolipoprotein. Int J Cancer. 2007;120(3):611-22.

24. Hoeller C, Pratscher B, Thallinger C, Winter D, Fink D, Kovacic B, et al. Gp80 (clusterin; TRPM-2) mRNA level is enhanced in human renal clear cell carcinomas. J Cancer Res Clin Oncol. 1994;120(3):186-8.

\section{Submit your next manuscript to BioMed Central and take full advantage of:}

- Convenient online submission

- Thorough peer review

- No space constraints or color figure charges

- Immediate publication on acceptance

- Inclusion in PubMed, CAS, Scopus and Google Scholar

- Research which is freely available for redistribution

Submit your manuscript at www.biomedcentral.com/submit
C Biomed Central 